Research Article

\title{
Aerodynamic Fields inside S-Shaped Baffled-Channel Air-Heat Exchangers
}

\author{
Younes Menni (D), ${ }^{1}$ Giulio Lorenzini, ${ }^{2}$ Ravinder Kumar $\left(\mathbb{D},{ }^{3}\right.$ Babak Mosavati, \\ and Saeed Nekoonam (iD ${ }^{5}$ \\ ${ }^{1}$ Unit of Research on Materials and Renewable Energies, Department of Physics, Faculty of Sciences, \\ Abou Bekr Belkaid University, Tlemcen, Algeria \\ ${ }^{2}$ Department of Engineering and Architecture, University of Parma, Parco Area delle Scienze, 181/A, Parma 43124, Italy \\ ${ }^{3}$ School of Mechanical Engineering, Lovely Professional University, Phagwara 144411, Punjab, India \\ ${ }^{4}$ Department of Mechanical and Ocean Engineering, Florida Atlantic University, Boca Raton, FL 33431, USA \\ ${ }^{5}$ Department of Renewable Energies and Environment, Faculty of New Sciences \& Technologies, University of Tehran, \\ Tehran, Iran
}

Correspondence should be addressed to Saeed Nekoonam; saeednekoonam@gmail.com

Received 23 November 2020; Accepted 29 April 2021; Published 11 May 2021

Academic Editor: Jun Ye

Copyright ( 2021 Younes Menni et al. This is an open access article distributed under the Creative Commons Attribution License, which permits unrestricted use, distribution, and reproduction in any medium, provided the original work is properly cited.

A numerical study of an especial heat exchanger (HE) equipped with complicated geometry baffles was performed in this research study. This shell-and-tube HE could be applied in various engineering applications like solar collectors. It can be acknowledged that generating longitudinal vortices in the flow results in enhancing the turbulent convective heat transfer. In order to generate these vortices, S-shaped baffles can be applied. It should be noted that computational analysis of shell-and-tube HEs is considered a challenging task due to these vortices. So, in this study, a commercial CFD software has been used for solving the problem and important equation and numerical approach used in the simulation have been explained. The aerodynamic aspect with respect to stream function, mean, axial, and transverse velocities, dynamic pressure, turbulent dissipation rate, turbulence kinetic energy, turbulent viscosity, and turbulence intensity fields was included in this research. This study reports many physical phenomena, such as the turbulence, instability, flow separation, and the appearance of reverse secondary currents. The average speed changed in different areas, where it is low next to the baffles. Velocity amounts are paramount around the upper channel's wall, starting from the upper left side of the last baffle to the exit. This increase in velocity can be justified by a reduction in flow area and pressure augmentation.

\section{Introduction}

During last decades, heat exchangers (HEs) have been prevailingly utilized in different industries and domestic applications $[1,2]$. As a result, numerous investigations have focused on various kinds of heat exchangers (HEs) with the purpose of enhancing their performance. In this way, a numerical and experimental study on plate HEs with utilizing paraffin wax in it has been carried out by Juaifer et al. [3]. Also, thermal performance of a parallel-plate $\mathrm{HE}$ fractionally filled with porous media has been numerically studied by Arasteh et al. [4]. According to the results, the heat transfer coefficient of the HE is enhanced up to $19.2 \%$. Additionally, Li et al. [5] used a numerical study to evaluate forced-convection heat transfer in a HE with inserting a twisted tape and using nanofluid. Furthermore, Aghayari et al. [6] performed an investigation focused on thermal performance of a double-pipe HE by inserting twisted tape and nanofluid. In another study, multilayer PCMs have been used in a tubular HE by Sadeghi et al. [7] for the aim of reducing the use of energy in industries. Moreover, both experimental and numerical studies have been performed by Maddah et al. [8] for the aim of enhancing the performance of heat pipe $\mathrm{HE}$ by using $\mathrm{CuO}$ /water nanofluid. As indicated 
in the results, the thermal performance of the HE was increased by using the nanofluid. Maddah et al. [9] examined a double-pipe $\mathrm{HE}$ with $\mathrm{Al}_{2} \mathrm{O}_{3}-\mathrm{TiO}_{2}$ hybrid nanofluid with different Reynolds numbers and concentrations. Sakhri et al. [10] experimentally examined the effect of using an earth-toair $\mathrm{HE}$ to provide a favorable condition in winter. The influence of using $\mathrm{Al}_{2} \mathrm{O}_{3}$ nanofluid in various kinds of HEs such as plate, double-pipe, and shell-and-tube HEs has been experimentally analyzed by Mansoury et al. [11]. According to the results, it was announced that an $11 \%$ enhancement of heat transfer coefficient was achieved in the plate HE. A study on a plate $\mathrm{HE}$ has been performed by SodagarAbardeh et al. [12] to find flow characteristics and optimum geometry of it by using the genetic algorithm. Also, a review on thermal and flow characteristics of compact fin-and-tube HEs has been performed by Adam et al. [13].

Recently, myriad engineering fields and sectors have used shell-and-tube HEs with baffles and fins. As a result of their prevailing usage, a main concern within researchers and scholars regarding these HEs can be mentioned as improving the performance. To address this issue, heat transfer and flow characteristics of shell-and-tube heat exchangers with segmental baffles and middle-overlapped helical baffles were experimentally investigated by Zhang et al. [14]. Also, by using the grid generation program Gambit and ANSYS Fluent, a model of a heat exchanger with middle-overlapped helical baffles has been simulated by Zhang et al. [15]. Miansari et al. [16] performed a numerical analysis to find the influences of circular grooves on shelland-tube HEs. Based on the results, the heat transfer rate was enhanced by $5 \%$. Menni et al. [17] simulated turbulent forced-convection flow in a channel with $\mathrm{V}$-shaped baffles. In another study, Menni et al. [18] numerically evaluated fluid flow characteristics adjacent to arc and flat-shaped baffles in shell-and-tube HEs. Based on the results, an improvement in the thermal performance could be achieved. Additionally, Hosseini et al. [19] simulated a shell-and-tube $\mathrm{HE}$ by utilizing CNT/water nanofluid with the purpose of evaluating heat transfer performance. Xiao et al. [20] used the CFD method to study fluid flow and thermal performance of heat exchangers equipped with various baffles tilt angles. In another study, liquid gas flow and its thermal performance in a heat exchanger at a pressure of $0.6 \mathrm{MPa}$ have been numerically investigated by Afrianto et al. [21]. Furthermore, You et al. [22] with a numerical approach analyzed the permeability and porosity for the aim of obtaining the shell side thermal hydraulic performances.

Also, Du et al. [23] examined overlapped helical baffled HEs to numerically study the influence of using distinct geometric parameters on flow resistance and thermal characteristics. A 3D CFD simulation has been presented by El Maakoul et al. [24] for the objective of studying and comparing heat transfer coefficient, the shell side flow distribution, and the pressure drop at low shell side flow rates in a newly established trefoil-hole, helical baffles, and conventional segmental baffles. Furthermore, the influence of using baffle clearances on a small-scale HE developed by HTRI software has been analyzed by Leoni et al. [25]. Also, the pressure drop and heat transfer performances of a shell-and-tube HE with helical baffles on shell side have been presented by Shinde and Chavan [26]. In another study, tube and shell HEs with helical baffle have been investigated by Gustyawan et al. [27]. Also, the thermal and flow characteristics of a shell-and-tube HE have been examined by Nagre et al. [28] with the use of CFD simulation and experimental approaches. Prajapati and Makwana [29] analyzed a shell-and-tube HE with continuous helical baffles, noncontinuous helical baffles, and segmental baffles HE with the CFD method. Furthermore, an innovative shell-and-tube $\mathrm{HE}$ with screw cinquefoil orifice baffles has been presented by Zhang et al. [30] to obviate defects of conventional shell-and-tube HEs with these baffles. Saeedan and Bahiraei [31] presented 3D simulations of shell side of shelland-tube $\mathrm{HE}$ with helical baffles for various values of helix angle and overlapping. Ma et al. [32] simulated the thermal performance and fluid flow properties of HE's shell sides with trefoilhole and quadrifoil-hole baffles. Also, a CFD model was performed on a shell-and-tube HE by Ambekar et al. [33] which was equipped with different baffle structures such as A-type and B-type flowers and single, double, and triple helical baffle. In another study, one segmental baffle HE (SEG) and five trisection helical baffle HEs $\left(10^{\circ} \mathrm{S}, 15^{\circ} \mathrm{S}, 20^{\circ} \mathrm{S}, 15^{\circ} \mathrm{E}\right.$, and $\left.20^{\circ} \mathrm{D}\right)$ have been compared by Dong et al. [34] using numerical simulation. Additionally, a numerical investigation has been performed on a helixchanger by Shinde and Hadgekar [35] for the aim of disclosing the influences of baffle inclination angle on the pressure drop and thermal performance of the HE equipped with center tube with various baffle inclination angles. Two innovative shell-and-tube HEs with louver baffles for energy conservation have been invented and designed by Lei et al. [36]. Additionally, with the objective of achieving knowledge regarding fundamental mechanism of shell side thermal improvement, a computational fluid dynamic simulation which contained inlet and outlet nozzles has been conducted by Zhou et al. [37]. On the other hand, Rashad [38-42], Rashad et al. [43-45], Chamkha et al. [46-49], Menni et al. [50-53], Ghalambaz et al. [54, 55], Mehryan et al. [56, 57], Sabour et al. [58], and Tahmasebi et al. [59] have studied the fluid flow effect that could be applied in solar systems.

Different configurations and distinct thermal and hydrodynamic boundary conditions have been applied in these works. Thus, the most prevailing applied method in simulating HEs and flow can be mentioned as CFD. The objective of this contribution can be mentioned as an analysis of turbulent air flow by utilizing computational fluid dynamics (CFD) in shelland-tube heat exchangers fitted with bottom and top wallmounted S-shaped baffles in a staggered manner. The calculation method of finite volumes, the turbulence model of standard k-epsilon, and the discretization algorithm of semiimplicit pressure linked equation were adopted in this research by using the CFD software Fluent.

\section{Computational Model}

The aim of this research can be stated as performing a numerical analysis of dynamic behavior of an incompressible Newtonian fluid (air) under the conditions of turbulent flow and constant property within a 2D horizontal rectangular channel (Figure 1). This study is a complementary flow analysis in the presence of S-baffles [49]. 


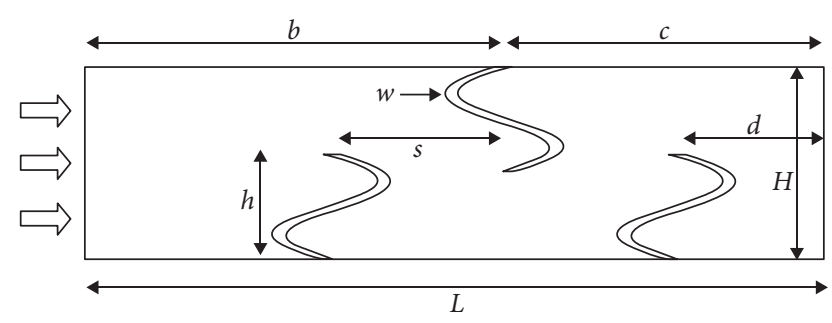

FIgURE 1: Geometrical model [49].

The transverse, solid-type, and S-upstream from baffles with different stations have been embedded into the channel and fastened to the bottom as well as top walls of the channel in a staggered manner for the aim of forcing recirculation cells to augment the mixing that results in the convective heat transfer. Consequently, a critical issue which must be specified is the flow in shell-and-tube HEs. Additionally, determining turbulent viscosity, turbulent dissipation rate, turbulence kinetic energy, dynamic pressure, velocity, stream function, and turbulence-intensity distributions as well as the existence and the extension of possible recycling cells can be enumerated as a crucial step. Table 1 reports the important geometry dimensions of the computational model under study $[49,60]$.

\section{Numerical Model}

The flow is steady, 2D, turbulent, incompressible, and Newtonian. The physical properties contributed to solid and fluid are constant. In this study, viscous dissipation, body forces, and radiation heat transfer are neglected. The computational domain and boundaries are presented as follows [49].

Inlet:

$$
\begin{aligned}
u & =U_{\text {in }}, \\
v & =0, \\
k_{\text {in }} & =0.005 U_{\text {in }}^{2}, \\
\varepsilon_{\text {in }} & =0.1 k_{\text {in }}^{2} .
\end{aligned}
$$

Outlet:

$$
\begin{aligned}
\frac{\partial u}{\partial x} & =0, \\
\frac{\partial v}{\partial x} & =0, \\
\frac{\partial k}{\partial x} & =0, \\
\frac{\partial \varepsilon}{\partial x} & =0, \\
P & =P_{\mathrm{atm}} .
\end{aligned}
$$

Walls:
TABLE 1: Dimensions of the geometry $(\mathrm{m})$.

\begin{tabular}{lc}
\hline S-baffle dimensions $(\mathrm{m})$ & Value \\
\hline Height, $h$ & 0.08 \\
Thickness, $w$ & 0.01 \\
Separation, $s$ & 0.120 \\
\hline Channel dimensions (m) & \\
Length, $L$ & 0.554 \\
Height, $H$ & 0.146 \\
Hydraulic diameter, $D_{h}$ & 0.167 \\
Distance (inlet-upper baffle), $b$ & 0.310 \\
Distance (outlet-upper baffle), $c$ & 0.234 \\
Distance (2 $2^{\text {nd }}$ lower baffle-outlet), $d$ & 0.104
\end{tabular}

$$
\begin{aligned}
& u=0, \\
& v=0, \\
& k=0, \\
& \varepsilon=0 .
\end{aligned}
$$

The calculation method of finite volumes [61], the turbulence model of standard $k$-epsilon [62], and the discretization algorithm of semi-implicit pressure linked equation with using ANSYS Fluent were considered. Various mesh node densities were realized, verified, and compared for the objective of evaluating the influence of mesh cell size on the numerical solution, and $245 \times 95$ nodes were regarded [49]. The detail on mathematical and numerical modeling can be found in Ref. [49]. As a validation, the obtained values for friction factor $\left(f_{0}\right)$ and average Nusselt number $\left(\mathrm{Nu}_{0}\right)$ [49] are compared with the achieved values based on Dittus-Boelter [63] and Petukhov [64] correlations under equivalent flow conditions. The comparison showed that the two results related to $\mathrm{Nu}_{0}$ and $f_{0}$ are in very good concordance.

\section{Results and Discussion}

The studied channel consists of three new transverse baffles of the shape "S." Starting with the display of air current lines (see Figure 2), regular distribution at the entrance of the channel (zone A) was detected. This distribution is disturbed in the vicinity of the first baffle located on the bottom surface of the channel (zone B). The air molecules collide with the baffle, turning towards the top of the channel (zone C). The sharp head on the front of the baffle represents the separation point of the current into three currents (zone D). The first is the main, from left to right (zone E). The second is a secondary made up of small and weakly recyclable cells in the upper front corner of the baffle (zone F). The third, also secondary, is made up of recyclable cells, large size but weak intensity, in the back of the same baffle (zone G). These secondary currents are carried in the opposite direction of the main stream. The main current moves over the first baffle and touches the upper wall of the channel and collides with the second baffle installed on the upper wall of the channel. The same phenomenon is formed next to this baffle. The current is split at the level of the upper head of the upper 


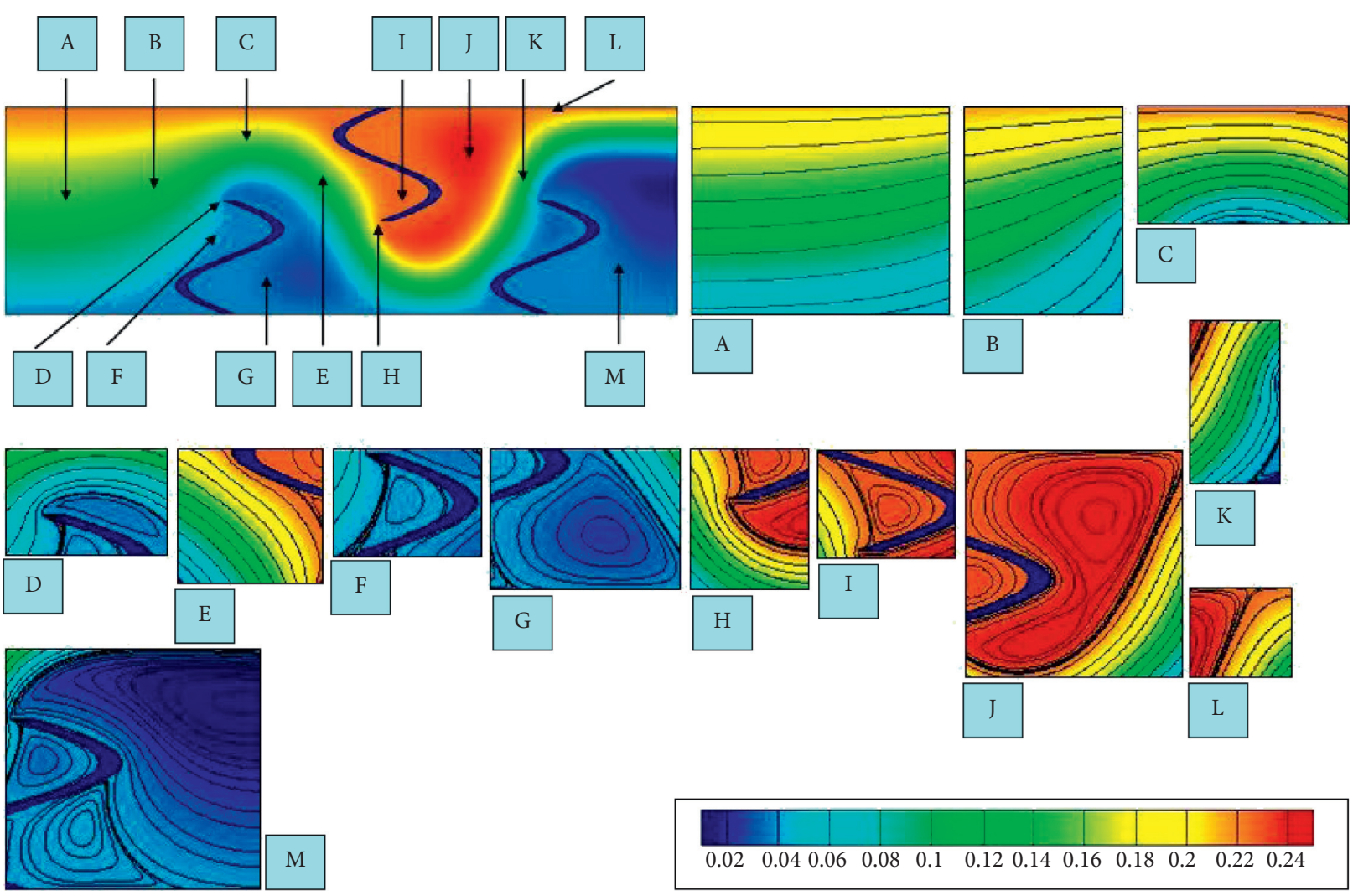

Figure 2: Stream function field distribution $(\mathrm{Kg} / \mathrm{s})$. Air flow is from left to right. $\mathrm{Re}=12,000$.

front (zone H). Reverse currents are weak in the lower front of this baffle (zone I), but the recirculation cells are large and strong in volume behind the same baffle (zone J). This current reaches the third baffle, and then it veers upward (zone $\mathrm{K}$ ). The top surface of the channel is reconnected (reattachment point, zone L) to its outlet, where there are rings and cells for recycling that are large and very thin behind the baffle to the outlet at the bottom of the channel, zone $\mathrm{M}$.

Pressure values rise above the first baffle as shown in zone A due to a decrease in flow area, while these values decrease in the lower sides, front and rear as depicted in zones B and C, respectively. This decrease in pressure values results in the formation of rings and cells of reverse secondary currents, namely, recycling areas, particularly in the back areas which is clear in Detail A. The pressure values rise at the main airway path, from left to right (zone D). The pressure values are high in the confined areas in the middle of the upper edges of the baffles and the channel's inner walls, especially next to the head of the second baffle (zone E) and in the vicinity of the lower left side of the third baffle (zone F) whereas the maximal values are present in the upper front of the same last (zone G) and as near the upper surface of the channel behind the identical baffle to the outlet (zone $\mathrm{H}$ ). There are also areas of low pressure in the front sides, especially at the back of each of the second and third baffles, where recycling cells are present which are depicted in Figure 3, Details B and C, respectively.
The mean velocity values vary with the region in the studied channel, in front, behind, and between the baffles. The air enters at regular and constant speed (zone A). This speed changes in different areas, where it is low next to the three baffles, zones B, C, D, E, F, G, H, I, J, K, and L while the velocity values rise in the vicinity of the upper left side of the first baffle (zone $M$ ). This increase in velocity can be justified since a reduction in flow area and pressure augmentation (zone N). The velocity value also increases in vicinity of the lower front edge of the second baffle (zone $\mathrm{O}$ ). Velocity amounts are paramount around the upper the channel's wall (zone P), starting from the upper left side of the third baffle (zone Q) to the exit (Figure 4).

The variations of velocity across the channel are represented in Figure 5. Axial velocity can be distinguished by significant quantities in the top of the first baffle (see Figure 6), critical values below the second baffle (see Figure 7), and extremely high values near the lower surface of the channel's upper wall versus the third baffle (see Figure 8).

This increment is due to the high pressure values in these areas (see Figures 9-11) owing to significant decline in the flow area of the fluid. Low velocities have negative values next to the baffles. These negative values are evidence of the presence of recycling cells next to these baffles. Five regions for recycling are due to the presence of the first baffle. The first zone is located next to the lower left side 


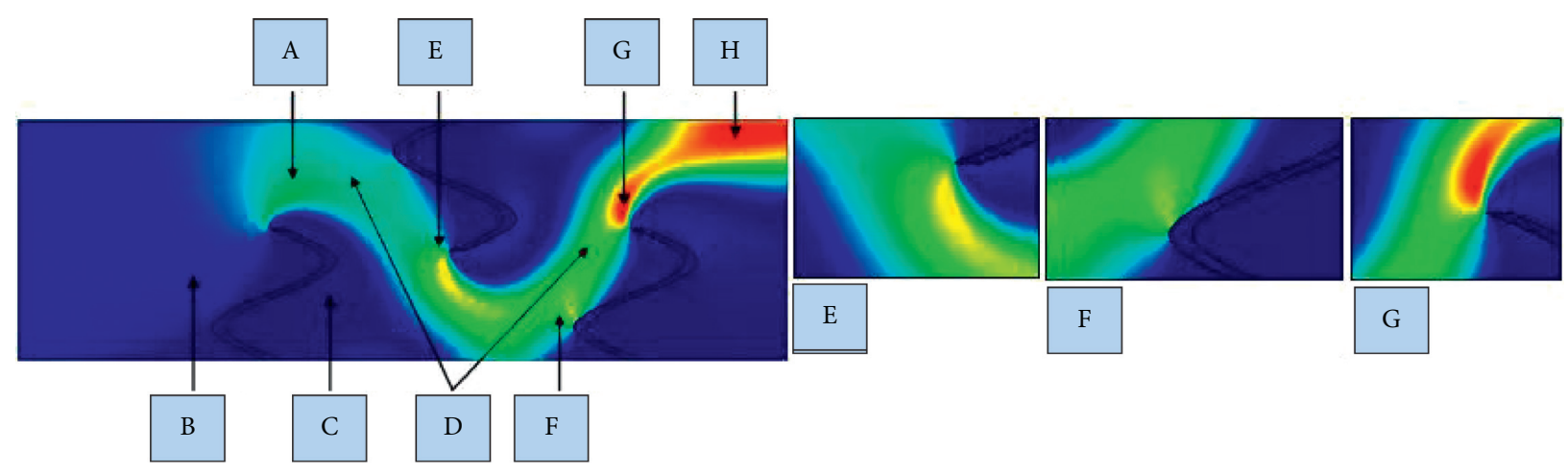

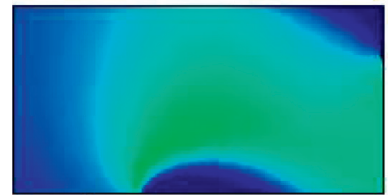

A

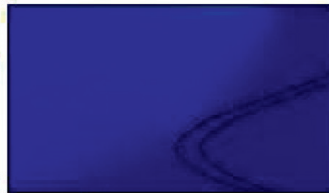

B

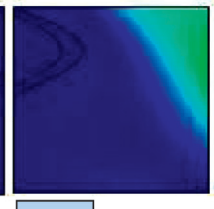

C

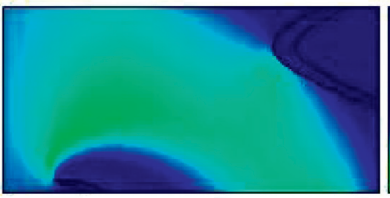

D

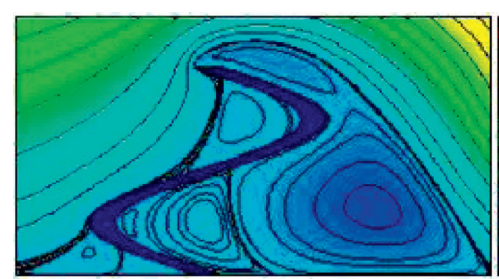

Detail A

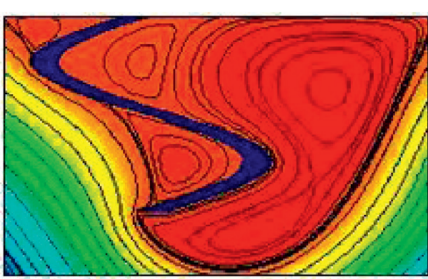

Detail B

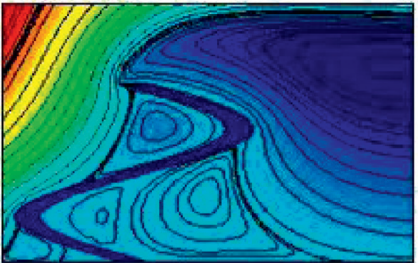

Detail C

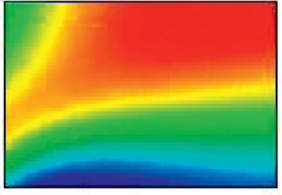

$\mathrm{H}$

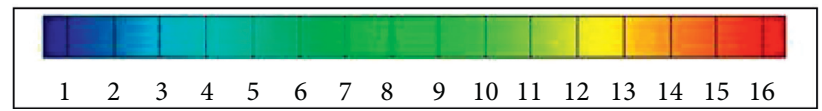

Figure 3: Dynamic pressure field distribution (Pa). Air flow is from left to right. $\operatorname{Re}=12,000$.

(zone A: see Figure 12). The second zone is adjacent to the left side in the top section (zone B: see Figure 13). The third zone is by the side of the top area (zone C: see Figure 14). The fourth region is next to the lower right corner (zone D: see Figure 15), while the fifth region is located behind the same baffle (zone E: see Figure 16), which has a large size, located in the limited area between the main stream (zone F), the upper right side (zone G), and the bottom surface of the channel (zone $\mathrm{H}$ ), in contact with the vortex which is located next to the lower right section of this same baffle (zone D). The same behavior is observed for the two remaining baffles. 

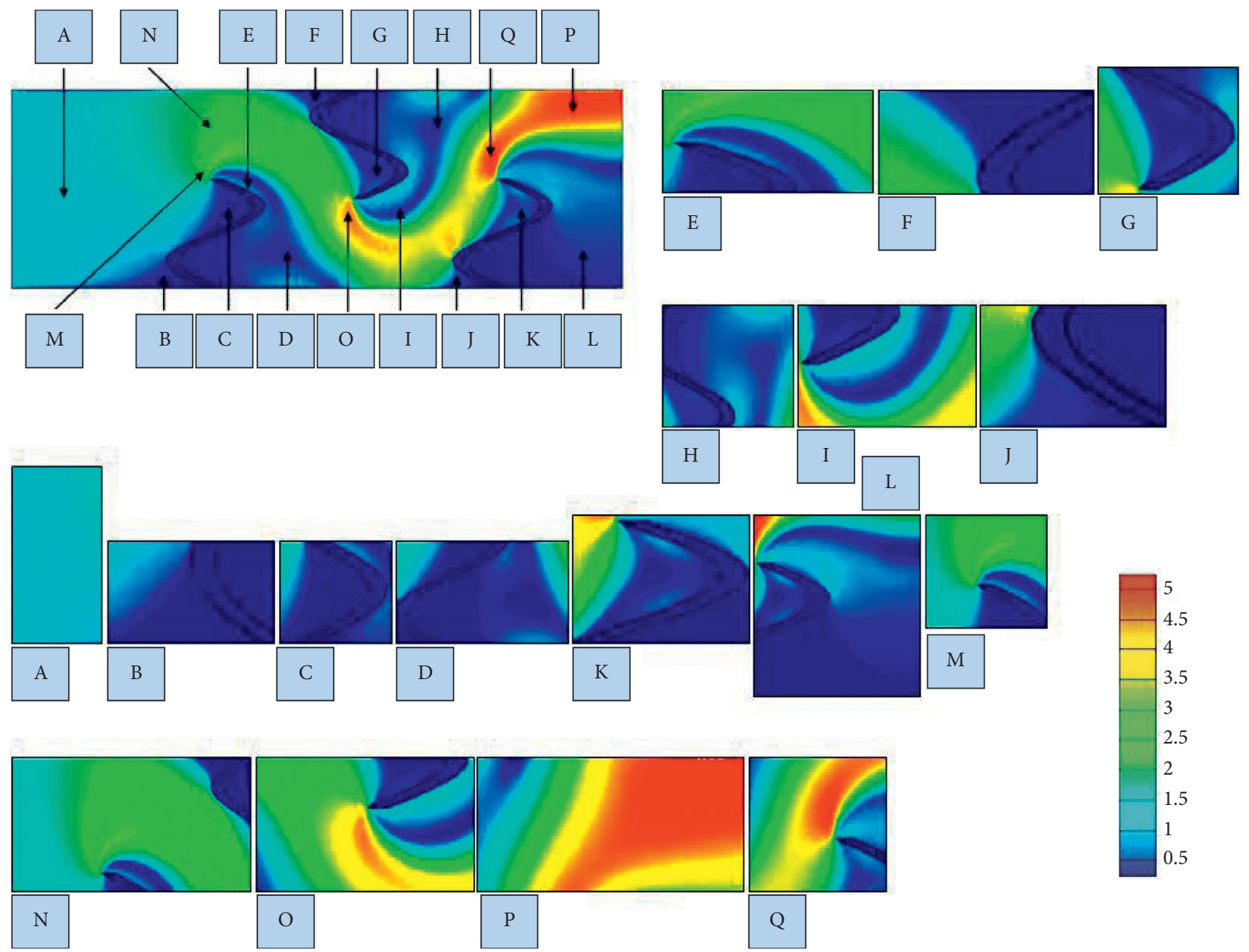

Figure 4: Mean velocity field distribution (m/s). Air flow is from left to right. $\operatorname{Re}=12,000$.

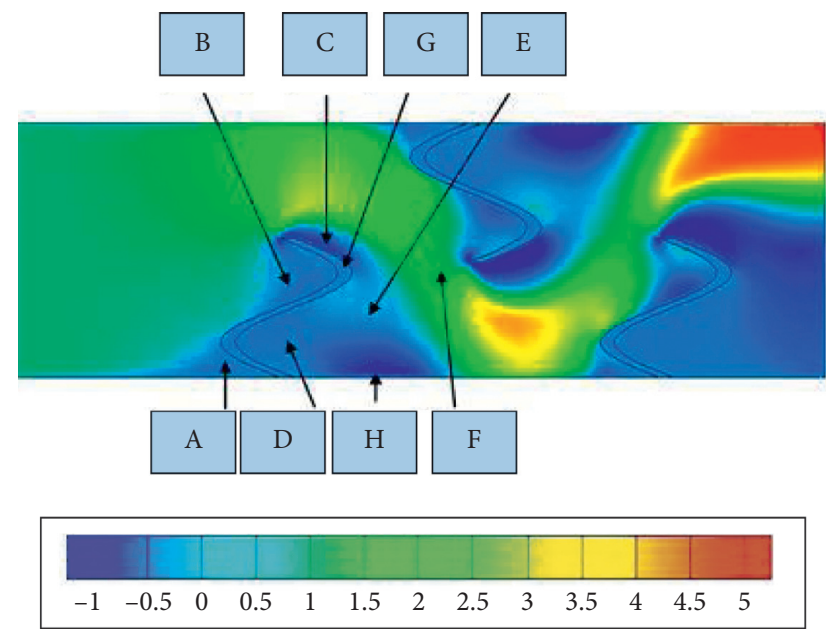

Figure 5: Axial velocity field distribution $(\mathrm{m} / \mathrm{s})$. Air flow is from left to right. $\operatorname{Re}=12,000$.

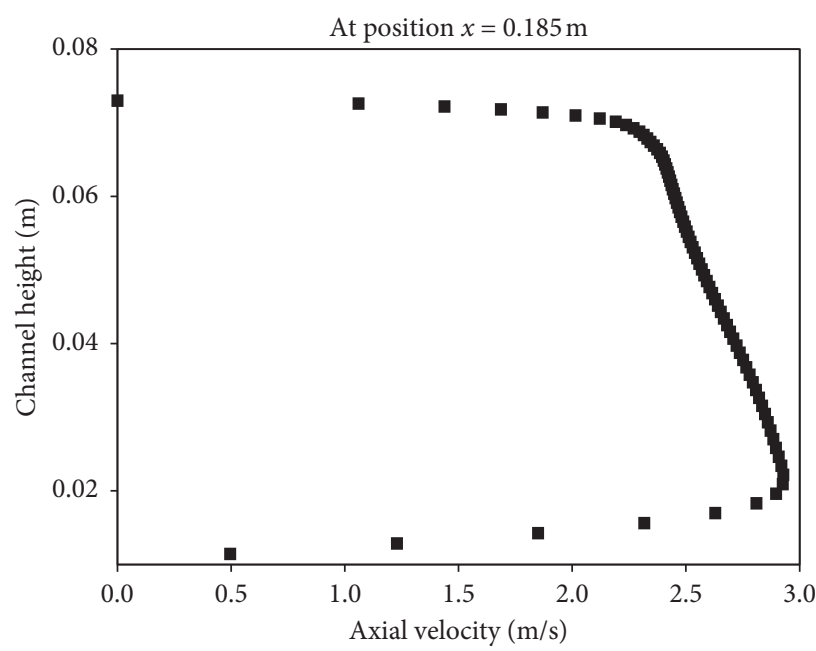

FIGURE 6: X-velocity profile above the first baffle; $\mathrm{Re}=12,000$. 


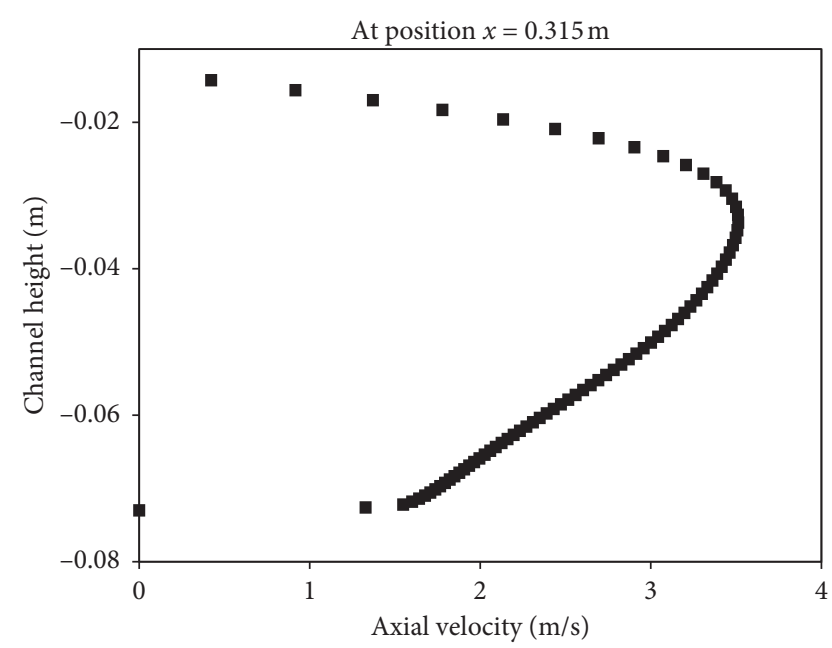

Figure 7: X-velocity profile below the second baffle; $\mathrm{Re}=12,000$.

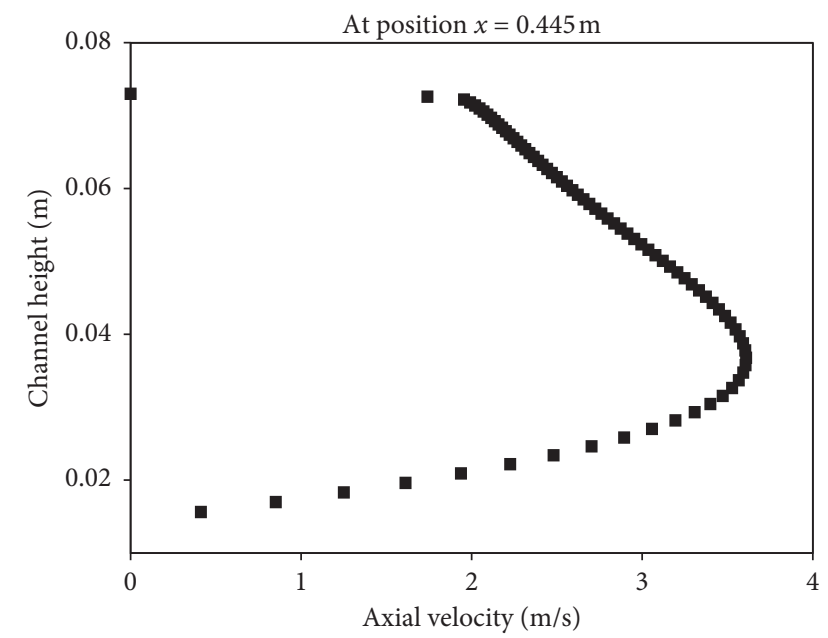

FIGURE 8: X-velocity profile above the third baffle; $\mathrm{Re}=12,000$.

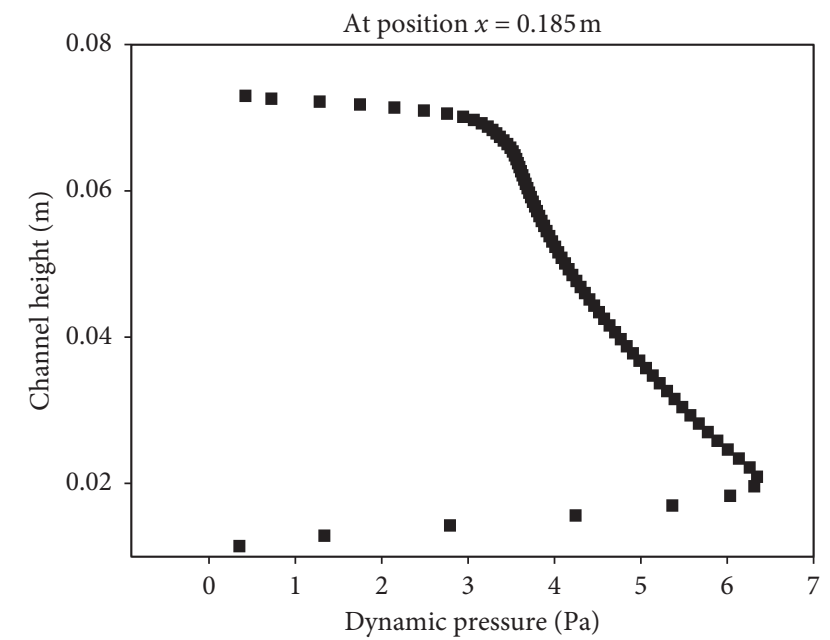

Figure 9: Dynamic pressure profile above the first baffle; $\operatorname{Re}=12,000$.

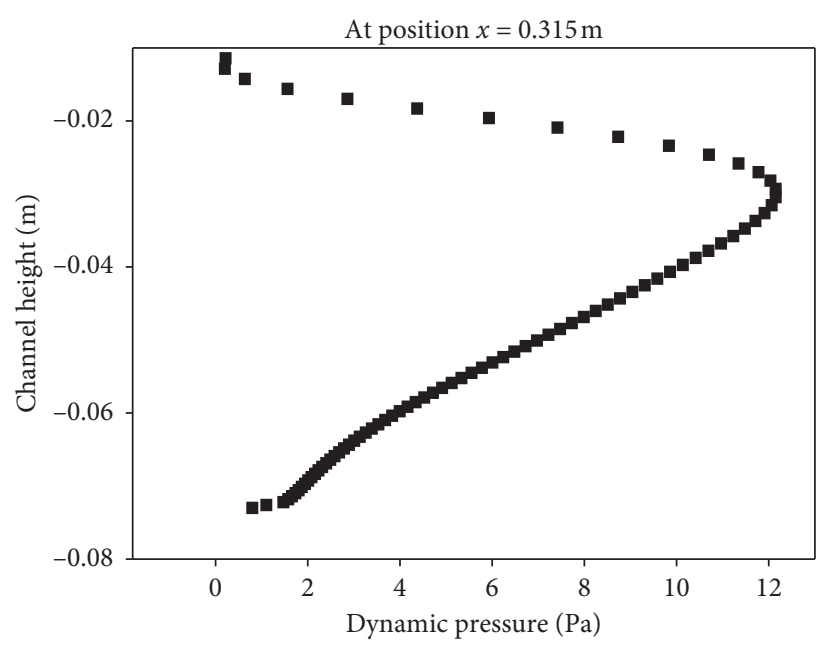

FIgURE 10: Dynamic pressure profile below the second baffle; $\operatorname{Re}=12,000$.

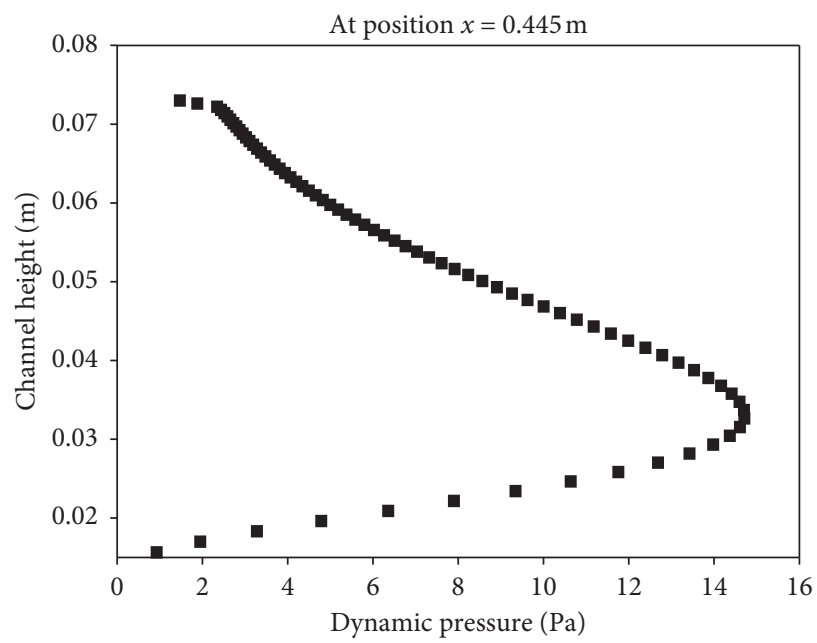

Figure 11: Dynamic pressure profile above the third baffle; $\operatorname{Re}=12,000$.

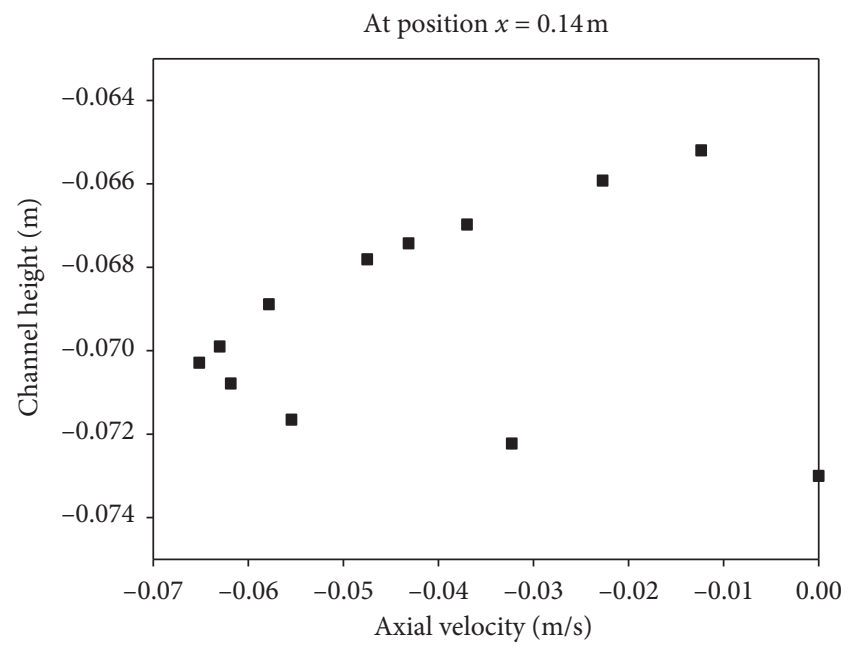

FIGURE 12: X-velocity profile next to the lower left side of the first baffle; $\operatorname{Re}=12,000$. 


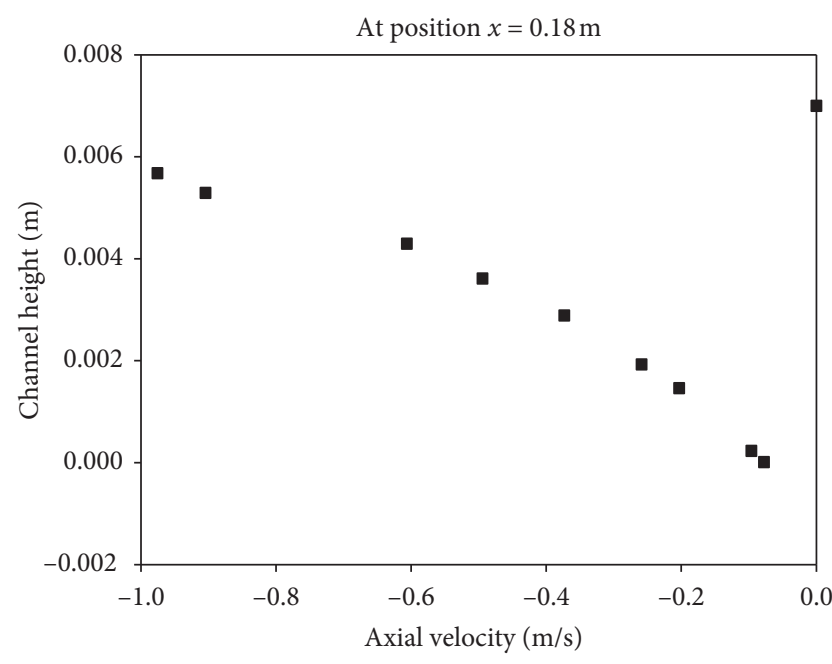

FIGURE 13: X-velocity profile next to the left side in the top section of the first baffle; $\operatorname{Re}=12,000$.

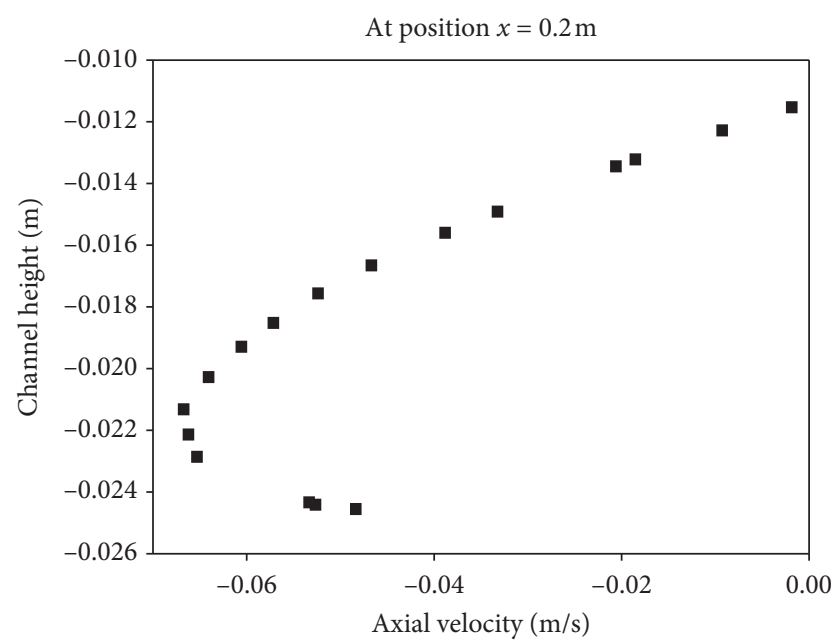

Figure 14: X-velocity profile next to the top area of the first baffle; $\operatorname{Re}=12,000$.

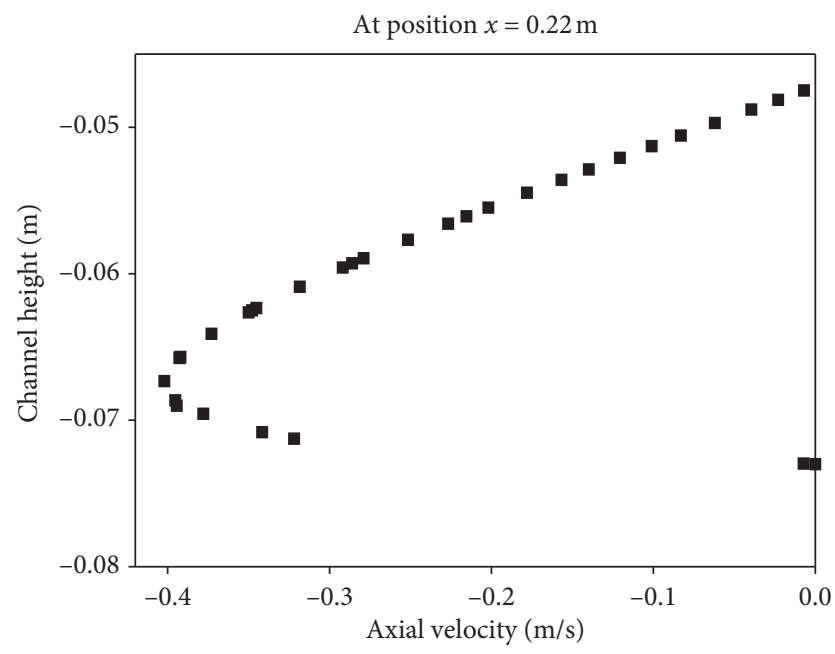

FIGURE 15: X-velocity profile next to the lower right corner of the first baffle; $\operatorname{Re}=12,000$.

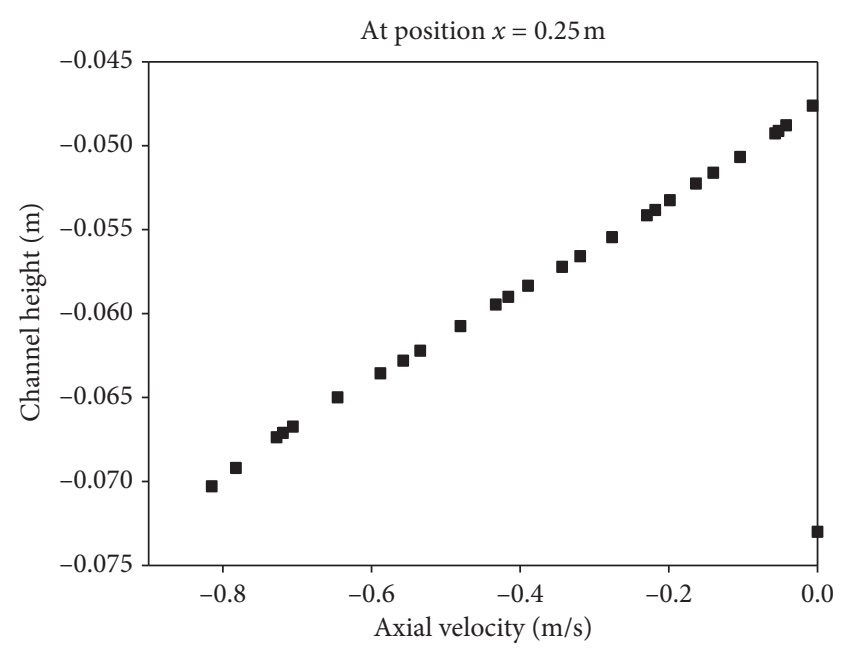

Figure 16: X-velocity profile downstream of the first baffle; $\operatorname{Re}=12,000$.

\section{Conclusion}

In this article, the air flow in a HE with three S-obstacles is studied by using CFD technique. In the addressed HE, three transverse, solid-type, S-upstream form baffles having different stations have been placed into the channel and fixed to their top and bottom walls, in a staggered manner for the aim of forcing recirculation cells to augment the mixing and hence the convective heat transfer. Also, for the objective of simulating turbulence effects, the turbulence model named $k$-epsilon is implemented. Furthermore, the validation and comparison with literature works are performed. The CFD analysis shows the following:

(i) The sharp head on the front of the baffle represented the separation point of the flow into three flows. The first is the major flow from left to right. The second is a secondary made up of small and weakly recyclable cells in the upper front corner of the baffle. The third, also secondary, is made up of recyclable cells, large size but weak intensity, in the back of the same baffle. These secondary flows are carried in the opposite direction of the main stream.

(ii) The pressure values are high in the confined zones in the middle of the upper edges of the baffles and the channel's inner walls, especially next to the head of the second baffle and adjacent to the lower left side of the third baffle whereas the maximal values are present in the upper front of the same last and as near the upper surface of the channel behind the same baffle to the outlet.

(iii) The pressure values decreased in the lower sides, front and rear. This decrease in pressure values results in the formation of rings and cells of reverse secondary currents, namely, recycling areas, particularly in the back areas.

(iv) Axial velocity can be distinguished by significant quantities in the top of the first baffle, critical values 
below the second baffle, and extremely high values near the lower surface of the channel's upper wall versus the third baffle. This increment is due to the high pressure values in these areas as a result of significant reduction in the flow area of the fluid.

(v) Five regions for recycling are due to the presence of the first baffle. The first zone is located next to the lower left side. The second zone is adjacent to the left side in the top section. The third zone is by the side of the top area. The fourth region is next to the lower right corner, while the fifth region is located behind the same baffle, which has a large size, located in the limited area between the main stream, the upper right side, and the bottom surface of the channel, in contact with the vortex which is located next to the lower right section of this same baffle. The same behavior was observed for the two remaining baffles.

(vi) Finally, the simulation mentioned many physical phenomena such as the turbulence, instability, flow separation, and the appearance of reverse secondary currents. As its data are confirmed by many previous numerical and experimental results, the suggested new model of finned and baffled HE channels allows an improvement in the dynamic behavior of many thermal devices such as flat plate solar collectors.

(vii) This study can be extended by the following:

(1) Three-dimensional study with new boundary conditions such as the effect of solar radiation instead of temperature

(2) Enhancing heat transfer using porous S-baffles

(3) Improving heat transfer using perforated S-baffles

(4) The effect of S-baffle dimensions on enhancing heat transfer

(5) The influence of both inlet and outlet channel on S-fin heat transfer

(6) Comparison of different S-baffle arrangements such as staggered, in-line, and parallel

(7) The effect of thermal-physical properties of the transport fluid on S-fin heat transfer

(8) The effect of S-fins with nanofluids on heat transfer and comparison of their performance with conventional fluids

(9) Influence of the inclined channel with S-fins on the heat transfer for laminar and turbulent flows

(10) Combination of S-fin, nanofluid, and porous media techniques to improve the performance

\section{Nomenclature}

$b: \quad$ Distance (inlet-upper baffle), $\mathrm{m}$

$c: \quad$ Distance (outlet-upper baffle), $\mathrm{m}$

$d$ : $\quad$ Distance ( $2^{\text {nd }}$ lower baffle-outlet), $\mathrm{m}$

$D_{h}$ : Hydraulic diameter of the exchanger, $\mathrm{m}$

$f_{0}: \quad$ Friction factor for the exchanger without baffles

$h$ : Height of the S-baffle, $m$

$H$ : Height of the exchanger, $m$ $k: \quad$ Turbulent kinetic energy, $\mathrm{m}^{2} \mathrm{~s}^{-2}$

$k_{\text {in }}: \quad \mathrm{k}$ at the exchanger inlet, $\mathrm{m}^{2} \mathrm{~s}^{-2}$

$L$ : $\quad$ Length of the exchanger, $\mathrm{m}$

$\mathrm{Nu}_{0}$ : Nusselt number for the exchanger without baffles

$P$ : $\quad$ Pressure, $\mathrm{Pa}$

$P_{\text {atm }}:$ Atmospheric pressure, Atm

$s: \quad$ Separation of the S-baffles, $m$

$u$ : $\quad$ Velocity in $X$-direction, $\mathrm{m} \mathrm{s}^{-1}$

$U_{\text {in }}: \quad X$-velocity at the exchanger inlet, $\mathrm{m} \mathrm{s}^{-1}$

$v: \quad$ Velocity in $Y$-direction, $\mathrm{m} \mathrm{s}^{-1}$

$w$ : Thickness of the S-baffle, $\mathrm{m}$

$\varepsilon: \quad$ Turbulent dissipation rate, $\mathrm{m}^{2} \mathrm{~s}^{-3}$

$\varepsilon_{\text {in }}: \quad \varepsilon$ at the exchanger inlet, $\mathrm{m}^{2} \mathrm{~s}^{-3}$.

\section{Data Availability}

The data used to support this study are not available due to ethical/legal/commercial restrictions.

\section{Conflicts of Interest}

The authors declare that they have no conflicts of interest.

\section{References}

[1] P. S. Raveendran and S. J. Sekhar, "Investigation on the energy and exergy efficiencies of a domestic refrigerator retrofitted with water-cooled condensers of shell-and-coil and brazedplate heat exchangers," Journal of Thermal Analysis and Calorimetry, vol. 136, no. 1, pp. 381-388, 2019.

[2] M. Monfared, A. Shahsavar, and M. R. Bahrebar, "Second law analysis of turbulent convection flow of boehmite alumina nanofluid inside a double-pipe heat exchanger considering various shapes for nanoparticle," Journal of Thermal Analysis and Calorimetry, vol. 135, no. 2, pp. 1521-1532, 2019.

[3] H. J. A. Juaifer, M. B. Ayani, and M. Poursadegh, "Melting process of paraffin wax inside plate heat exchanger: experimental and numerical study," Journal of Thermal Analysis and Calorimetry, vol. 140, no. 3, pp. 905-916, 2020.

[4] H. Arasteh, R. Mashayekhi, M. Ghaneifar, D. Toghraie, and M. Afrand, "Heat transfer enhancement in a counter-flow sinusoidal parallel-plate heat exchanger partially filled with porous media using metal foam in the channels' divergent sections," Journal of Thermal Analysis and Calorimetry, vol. 141, no. 5, pp. 1669-1685, 2019.

[5] Z. Li, M. Sheikholeslami, M. Jafaryar, A. Shafee, and A. J. Chamkha, "Investigation of nanofluid entropy generation in a heat exchanger with helical twisted tapes," Journal of Molecular Liquids, vol. 266, pp. 797-805, 2018.

[6] R. Aghayari, H. Maddah, S. M. Pourkiaei, M. H. Ahmadi, L. Chen, and M. Ghazvini, "Theoretical and experimental studies of heat transfer in a double-pipe heat exchanger equipped with twisted tape and nanofluid," The European Physical Journal Plus, vol. 135, no. 2, pp. 1-26, 202013522020.

[7] H. M. Sadeghi, M. Babayan, and A. Chamkha, "Investigation of using multi-layer PCMs in the tubular heat exchanger with periodic heat transfer boundary condition," International Journal of Heat and Mass Transfer, vol. 147, p. 118970, 2020.

[8] H. Maddah, M. Ghazvini, and M. H. Ahmadi, "Predicting the efficiency of $\mathrm{CuO}$ /water nanofluid in heat pipe heat exchanger using neural network," International Communications in Heat and Mass Transfer, vol. 104, pp. 33-40, 2019. 
[9] H. Maddah, R. Aghayari, M. Mirzaee, M. H. Ahmadi, M. Sadeghzadeh, and A. J. Chamkha, "Factorial experimental design for the thermal performance of a double pipe heat exchanger using $\mathrm{Al} 2 \mathrm{O} 3-\mathrm{TiO} 2$ hybrid nanofluid," International Communications in Heat and Mass Transfer, vol. 97, pp. 92-102, 2018.

[10] N. Sakhri, Y. Menni, A. J. Chamkha et al., "Study of heat and mass transfer through an earth to air heat exchanger equipped with fan in South west of Algeria," International Journal of Heat and Technology, vol. 37, no. 3, pp. 689-695, 2019.

[11] D. Mansoury, F. I. Doshmanziari, A. Kiani, A. J. Chamkha, and M. Sharifpur, "Heat transfer and flow characteristics of Al2O3/water nanofluid in various heat exchangers: experiments on counter flow," Heat Transfer Engineering, vol. 41, no. 3, pp. 220-234, 2020.

[12] J. Sodagar-Abardeh, A. Ebrahimi-Moghadam, M. FarzanehGord, and A. Norouzi, "Optimizing chevron plate heat exchangers based on the second law of thermodynamics and genetic algorithm," Journal of Thermal Analysis and Calorimetry, vol. 139, no. 6, pp. 3563-3576, 2020.

[13] A. Y. Adam, A. N. Oumer, G. Najafi, M. Ishak, M. Firdaus, and T. B. Aklilu, "State of the art on flow and heat transfer performance of compact fin-and-tube heat exchangers," Journal of Thermal Analysis and Calorimetry, vol. 139, no. 4, pp. 2739-2768, 2020.

[14] J.-F. Zhang, B. Li, W.-J. Huang, Y.-G. Lei, Y.-L. He, and W.-Q. Tao, "Experimental performance comparison of shellside heat transfer for shell-and-tube heat exchangers with middle-overlapped helical baffles and segmental baffles," Chemical Engineering Science, vol. 64, no. 8, pp. 1643-1653, 2009.

[15] J.-F. Zhang, Y.-L. He, and W.-Q. Tao, "3D numerical simulation on shell-and-tube heat exchangers with middle-overlapped helical baffles and continuous baffles - Part I: numerical model and results of whole heat exchanger with middle-overlapped helical baffles," International Journal of Heat and Mass Transfer, vol. 52, no. 23-24, pp. 5371-5380, 2009.

[16] M. Miansari, M. A. Valipour, H. Arasteh, and D. Toghraie, "Energy and exergy analysis and optimization of helically grooved shell and tube heat exchangers by using Taguchi experimental design," Journal of Thermal Analysis and Calorimetry, vol. 139, no. 5, pp. 3151-3164, 2020.

[17] Y. Menni, A. Azzi, and A. J. Chamkha, "Computational thermal analysis of turbulent forced-convection flow in an air channel with a flat rectangular fin and downstream v-shaped baffle," Heat Transfer Research, vol. 50, no. 18, pp. 1781-1818, 2019.

[18] Y. Menni, A. Chamkha, A. Azzi, C. Zidani, and B. Benyoucef, "Study of air flow around flat and arc-shaped baffles in shelland-tube heat exchangers," Mathematical Modelling of Engineering Problems, vol. 6, no. 1, pp. 77-84, 2019.

[19] S. Masoud Hosseini, M. R. Safaei, P. Estellé, and S. Hadi Jafarnia, "Heat transfer of water-based carbon nanotube nanofluids in the shell and tube cooling heat exchangers of the gasoline product of the residue fluid catalytic cracking unit," Journal of Thermal Analysis and Calorimetry, vol. 140, no. 1, pp. 351-362, 2019.

[20] X. Xiao, L. Zhang, X. Li, B. Jiang, X. Yang, and Y. Xia, "Numerical investigation of helical baffles heat exchanger with different Prandtl number fluids," International Journal of Heat and Mass Transfer, vol. 63, pp. 434-444, 2013.

[21] H. Afrianto, M. R. Tanshen, B. Munkhbayar, U. Tony Suryo, H. Chung, and H. Jeong, "A numerical investigation on LNG flow and heat transfer characteristic in heat exchanger," International Journal of Heat and Mass Transfer, vol. 68, pp. 110-118, 2014.

[22] Y. You, A. Fan, S. Huang, and W. Liu, "Numerical modeling and experimental validation of heat transfer and flow resistance on the shell side of a shell-and-tube heat exchanger with flower baffles," International Journal of Heat and Mass Transfer, vol. 55, no. 25-26, pp. 7561-7569, 2012.

[23] T. Du, W. Du, K. Che, and L. Cheng, "Parametric optimization of overlapped helical baffled heat exchangers by Taguchi method," Applied Thermal Engineering, vol. 85, pp. 334-339, 2015.

[24] A. El Maakoul, A. Laknizi, S. Saadeddine et al., "Numerical comparison of shell-side performance for shell and tube heat exchangers with trefoil-hole, helical and segmental baffles," Applied Thermal Engineering, vol. 109, pp. 175-185, 2016.

[25] G. Batalha Leoni, T. Suaiden Klein, and R. de Andrade Medronho, "Assessment with computational fluid dynamics of the effects of baffle clearances on the shell side flow in a shell and tube heat exchanger," Applied Thermal Engineering, vol. 112, pp. 497-506, 2017.

[26] S. Shinde and U. Chavan, "Numerical and experimental analysis on shell side thermo-hydraulic performance of shell and tube heat exchanger with continuous helical FRP baffles," Thermal Science and Engineering Progress, vol. 5, pp. 158-171, 2018.

[27] B. E. Gustyawan, "A CFD analysis of helical baffle variation in shell and tube heat exchanger - google Search," Journal of Mechanical Science and Technology, vol. 3, 2018.

[28] G. P. Nagre, "Comparative thermal performance analysis of shell and tube heat exchanger with and without fins by using CFD," International Journal of Research in Engineering and Technology, vol. 4, 2018.

[29] S. Prajapati and M. N. Makwana, "CFD analysis of shell and tube type heat exchanger and improvement in non-continuous helical baffle," International Journal of Research in Engineering and Technology, vol. 3, 2015.

[30] X. Zhang, D. Han, W. He, C. Yue, and W. Pu, "Numerical simulation on a novel shell-and-tube heat exchanger with screw cinquefoil orifice baffles," Advances in Mechanical Engineering, vol. 9, no. 8, Article ID 168781401771766, 2017.

[31] M. Saeedan and M. Bahiraei, "Effects of geometrical parameters on hydrothermal characteristics of shell-and-tube heat exchanger with helical baffles: numerical investigation, modeling and optimization," Chemical Engineering Research and Design, vol. 96, pp. 43-53, 2015.

[32] L. Ma, K. Wang, M. Liu et al., "Numerical study on performances of shell-side in trefoil-hole and quatrefoil-hole baffle heat exchangers," Applied Thermal Engineering, vol. 123, pp. 1444-1455, 2017.

[33] A. S. Ambekar, R. Sivakumar, N. Anantharaman, and M. Vivekenandan, "CFD simulation study of shell and tube heat exchangers with different baffle segment configurations," Applied Thermal Engineering, vol. 108, pp. 999-1007, 2016.

[34] C. Dong, X.-F. Zhou, R. Dong et al., "An analysis of performance on trisection helical baffles heat exchangers with diverse inclination angles and baffle structures," Chemical Engineering Research and Design, vol. 121, pp. 421-430, 2017.

[35] S. S. Shinde and P. V. Hadgekar, "Numerical comparison on Shell side performance of Helixchanger with center tube with different helix angles," International Journal of Scientific and Research Publication, vol. 3, 2013.

[36] Y. Lei, Y. Li, S. Jing, C. Song, Y. Lyu, and F. Wang, "Design and performance analysis of the novel shell-and-tube heat 
exchangers with louver baffles," Applied Thermal Engineering, vol. 125, pp. 870-879, 2017.

[37] G.-Y. Zhou, J. Xiao, L. Zhu, J. Wang, and S.-T. Tu, "A numerical study on the shell-side turbulent heat transfer enhancement of shell-and-tube heat exchanger with trefoil-hole baffles," Energy Procedia, vol. 75, pp. 3174-3179, 2015.

[38] A. M. Rashad, "Impact of thermal radiation on MHD slip flow of a ferrofluid over a non-isothermal wedge," Journal of Magnetism and Magnetic Materials, vol. 422, pp. 25-31, 2017.

[39] A. Rashad, "Unsteady nanofluid flow over an inclined stretching surface with convective boundary condition and anisotropic slip impact," International Journal of Heat and Technology, vol. 35, no. 1, pp. 82-90, 2017.

[40] A. M. Rashad, "Impact of anisotropic slip on transient three dimensional MHD flow of ferrofluid over an inclined radiate stretching surface," Journal of the Egyptian Mathematical Society, vol. 25, no. 2, pp. 230-237, 2017.

[41] A. M. Rashad, "Natural convection boundary layer flow along a sphere embedded in a porous medium filled with a nanofluid," Latin American Applied Research, vol. 44, no. 2, pp. 149-157, 2014.

[42] A. M. Rashad, "Effects of radiation and variable viscosity on unsteady MHD flow of a rotating fluid from stretching surface in porous medium," Journal of the Egyptian Mathematical Society, vol. 22, no. 1, pp. 134-142, 2014.

[43] A. M. Rashad, M. A. Ismael, A. J. Chamkha, and M. A. Mansour, "MHD mixed convection of localized heat source/sink in a nanofluid-filled lid-driven square cavity with partial slip," Journal of the Taiwan Institute of Chemical Engineers, vol. 68, pp. 173-186, 2016.

[44] A. M. Rashad, M. M. Rashidi, G. Lorenzini, S. E. Ahmed, and A. M. Aly, "Magnetic field and internal heat generation effects on the free convection in a rectangular cavity filled with a porous medium saturated with $\mathrm{Cu}$-water nanofluid," International Journal of Heat and Mass Transfer, vol. 104, pp. 878-889, 2017.

[45] A. M. Rashad, A. J. Chamkha, and S. M. M. El-Kabeir, "Effect of chemical reaction on heat and mass transfer by mixed convection flow about a sphere in a saturated porous media," International Journal of Numerical Methods for Heat \& Fluid Flow, vol. 21, no. 4, pp. 418-433, 2011.

[46] A. J. Chamkha and A. M. Rashad, "Natural convection from a vertical permeable cone in a nanofluid saturated porous media for uniform heat and nanoparticles volume fraction fluxes," International Journal of Numerical Methods for Heat \& Fluid Flow, vol. 22, no. 8, pp. 1073-1085, 2012.

[47] A. J. Chamkha, S. M. M. EL-Kabeir, and A. M. Rashad, "Heat and mass transfer by non-Darcy free convection from a vertical cylinder embedded in porous media with a temperature-dependent viscosity," International Journal of Numerical Methods for Heat \& Fluid Flow, vol. 21, no. 7, pp. 847-863, 2011.

[48] A. J. Chamkha, A. Doostanidezfuli, E. Izadpanahi, and M. Ghalambaz, "Phase-change heat transfer of single/hybrid nanoparticles-enhanced phase-change materials over a heated horizontal cylinder confined in a square cavity," Advanced Powder Technology, vol. 28, no. 2, pp. 385-397, 2017.

[49] A. J. Chamkha, Y. Menni, and H. Ameur, "Thermal-aerodynamic performance measurement of air heat transfer fluid mechanics over s-shaped fins in shell-and-tube heat exchangers," Journal of Applied and Computational Mechanics, vol. 7, no. 2, 2021.

[50] Y. Menni, A. Azzi, A. J. Chamkha, and S. Harmand, “Analysis of fluid dynamics and heat transfer in a rectangular duct with staggered baffles," Journal of Applied and Computational Mechanics, vol. 5, no. 2, pp. 231-248, 2019.

[51] Y. Menni, A. Azzi, A. Azzi, and A. J. Chamkha, "Optimal thermo aerodynamic performance of s-shaped baffled channels," Journal of Mechanical and Engineering Sciences, vol. 12, no. 3, pp. 3888-3913, 2018.

[52] Y. Menni, A. Azzi, and A. Chamkha, "Modeling and analysis of solar air channels with attachments of different shapes," International Journal of Numerical Methods for Heat \& Fluid Flow, vol. 29, no. 5, pp. 1815-1845, 2019.

[53] Y. Menni, A. J. Chamkha, A. Azzi, and B. Benyoucef, "Mathematical modelling and numerical simulation of shelland-tube heat exchangers with s-shaped turbulators," World Journal of Modelling and Simulation, vol. 15, no. 3, pp. 213227, 2019.

[54] M. Ghalambaz, E. Jamesahar, M. A. Ismael, and A. J. Chamkha, "Fluid-structure interaction study of natural convection heat transfer over a flexible oscillating fin in a square cavity," International Journal of Thermal Sciences, vol. 111, pp. 256-273, 2017.

[55] M. Ghalambaz, A. Doostani, E. Izadpanahi, and A. J. Chamkha, "Phase-change heat transfer in a cavity heated from below: the effect of utilizing single or hybrid nanoparticles as additives," Journal of the Taiwan Institute of Chemical Engineers, vol. 72, pp. 104-115, 2017.

[56] S. A. M. Mehryan, A. J. Chamkha, M. A. Ismael, and M. Ghalambaz, "Fluid-structure interaction analysis of free convection in an inclined square cavity partitioned by a flexible impermeable membrane with sinusoidal temperature heating," Meccanica, vol. 52, no. 11-12, pp. 2685-2703, 2017.

[57] S. A. M. Mehryan, M. Ghalambaz, and M. Izadi, "Conjugate natural convection of nanofluids inside an enclosure filled by three layers of solid, porous medium and free nanofluid using Buongiorno's and local thermal non-equilibrium models," Journal of Thermal Analysis and Calorimetry, vol. 135, no. 2, pp. 1047-1067, 2019.

[58] M. Sabour, M. Ghalambaz, and A. Chamkha, "Natural convection of nanofluids in a cavity: criteria for enhancement of nanofluids," International Journal of Numerical Methods for Heat \& Fluid Flow, Emerald Group Publishing Ltd., vol. 27, no. 7, pp. 1504-1534, 2017.

[59] A. Tahmasebi, M. Mahdavi, and M. Ghalambaz, "Local thermal nonequilibrium conjugate natural convection heat transfer of nanofluids in a cavity partially filled with porous media using Buongiorno's model," Numerical Heat Transfer, Part A: Applications, vol. 73, no. 4, pp. 254-276, 2018.

[60] L. C. Demartini, H. A. Vielmo, and S. V. Möller, "Numeric and experimental analysis of the turbulent flow through a channel with baffle plates," Journal of the Brazilian Society of Mechanical Sciences and Engineering, vol. 26, no. 2, pp. 153-159, 2004.

[61] S. V. Patankar, Numerical Heat Transfer and Fluid Flow, McGraw-Hill, New York, NY, USA, 1980.

[62] B. E. Launder and D. B. Spalding, "The numerical computation of turbulent flows," Computer Methods in Applied Mechanics and Engineering, vol. 3, no. 2, pp. 269-289, 1974.

[63] F. W. Dittus and L. M. K. Boelter, "Heat transfer in automobile radiators of tubular type," International Communications in Heat and Mass Transfer, vol. 12, no. 1, pp. 3-22, 1985.

[64] B. S. Petukhov, "Heat transfer and friction in turbulent pipe flow with variable physical properties," Advances in Heat Transfer, vol. 6, pp. 503-564, 1970. 